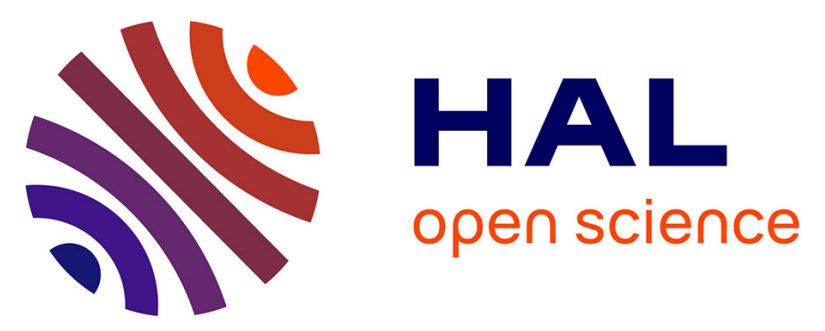

\title{
Phosphorous compounds as flame retardants for polybutylene succinate/flax biocomposite: Additive versus reactive route
}

Gaelle Dorez, Aurélie Taguet, Laurent Ferry, José-Marie Lopez-Cuesta

\section{- To cite this version:}

Gaelle Dorez, Aurélie Taguet, Laurent Ferry, José-Marie Lopez-Cuesta. Phosphorous compounds as flame retardants for polybutylene succinate/flax biocomposite: Additive versus reactive route. Polymer Degradation and Stability, 2014, 102, pp.152-159. 10.1016/j.polymdegradstab.2014.01.018 . hal-02914362

\section{HAL Id: hal-02914362 \\ https://hal.science/hal-02914362}

Submitted on 1 Jun 2021

HAL is a multi-disciplinary open access archive for the deposit and dissemination of scientific research documents, whether they are published or not. The documents may come from teaching and research institutions in France or abroad, or from public or private research centers.
L'archive ouverte pluridisciplinaire HAL, est destinée au dépôt et à la diffusion de documents scientifiques de niveau recherche, publiés ou non, émanant des établissements d'enseignement et de recherche français ou étrangers, des laboratoires publics ou privés. 


\title{
Phosphorous compounds as flame retardants for polybutylene succinate/flax biocomposite: Additive versus reactive route
}

\author{
Gaëlle Dorez, Aurélie Taguet, Laurent Ferry*, José-Marie Lopez Cuesta \\ C2MA, Ecole des Mines d'Alès, 30100 Alès, France
}

\section{A B S T R A C T}

This paper investigates the effect of three phosphorous compounds on the thermal and fire behavior of $\mathrm{PBS} /$ flax biocomposites: ammonium polyphosphate (APP), dihydrogen ammonium phosphate (DAP) and phosphoric acid (PA). A comparison of the additive and reactive routes for the fireproofing of biocomposites is investigated by TGA, PCFC and cone calorimetry.

The incorporation by additive route of APP, DAP and PA in biocomposites leads to the charring effect of flax fibers due to the phosphorylation and the dehydration of the cellulose, (the main component of flax fibers). PA leads to a lower condensed phase action compared to APP and DAP. PBS hot hydrolysis is also highlighted due to the presence of phosphorous compounds in the matrix. In the reactive route, DAP and PA are grafted onto flax fibers. The first temperature of degradation, assigned to flax degradation, is progressively shifted to lower temperature with increasing grafting rate while the amount of residue is also enhanced. Using this route, no PBS hydrolysis occurs. The proximity of the phosphorous compound with the flax fibers allows the formation of a strong char at lower phosphorus content. This char residue acts as a protective layer that limits gas and heat transfer, allowing the decrease of pHRR and MARHE.

\author{
Keywords: \\ Flax \\ Biocomposites \\ Surface modification \\ Ammonium polyphosphate \\ Dihydrogen ammonium phosphate \\ Phosphoric acid
}

\section{Introduction}

During the last years, the use of biocomposites (biopolymers reinforced by natural fibers) in sectors such as building, transportation or electrical equipment has generated a great interest [1]. This kind of materials offers many advantages like low cost, low density, low abrasiveness during processing or renewable origin, that make them a credible alternative to traditional glass fiber composites. However, the poor compatibility between fibers and matrix [2], the thermal and fire sensitivity [3-5] still limit their use in the above-mentioned applications. Thus, the improvement of the reaction to fire of biocomposites represents a stimulating challenge.

Until now, a limited number of papers has been published on flame retardancy of biocomposites. Most of them are dedicated to materials using polylactic acid (PLA) as matrix. Some researchers have brought out the interest of nanoparticles like expandable graphite [6], multi-walled carbon nanotubes or sepiolite nanoclays [7] as fire retardant agent (FR). But the most commonly

\footnotetext{
* Corresponding author. Tel.: +33 466785358.

E-mail address: laurent.ferry@mines-ales.fr (L. Ferry).
}

employed FRs in biocomposites remain the phosphorous compounds [8-11]. These FRs could be used either by direct incorporation into polymer matrix during the process or by impregnation or grafting onto natural fibers. Schartel et al. [6] studied the incorporation of APP in PP/flax biocomposites. They delivered a comprehensive characterization of the fire response for forced flaming combustion. Matkó et al. [9] also observed the effect of APP in PP/wood flake. In this study, the influence of the interface between the matrix and wood flakes was evidenced. The surface modification of the wood flakes by alcoxysilane improves the compatibility, but also the thermal stability of the biocomposite.

Several authors have demonstrated the interest to modify natural fiber surface using phosphorous compounds [8,10,11]. Shumao et al. [8] used APP as FR in PLA/ramie composite. APP was either directly added in the PLA matrix or deposited onto the ramie surface. The authors showed that the targeted action of APP on the fibers may inhibit mass transfer in the combustion zone and thus improves the fire behavior of the composite. However UL94 rating could not be changed due to a too low APP loading, contrary to direct incorporation in the matrix. The best results were obtained by combining both strategies. Chen et al. [11] have compared APP and microencapsulated APP (MAPP) as flame retardant in PLA/ 
ramie biocomposites. The objective of their work was to study the fire behavior of these biocomposites after UV irradiation and hydrothermal aging. The combined use of MAPP in the matrix and deposited onto the fibers leads to the best aging resistance since UL94 rating decreases only from V0 to V1 after 21 days exposure. This result was attributed to the good dispersion of MAPP in the matrix and to the good interaction between ramie and MAPP. Since APP is almost insoluble, other forms of ammonium phosphate have been used to achieve grafting onto natural fibers. Suardana et al. studied the grafting of diammonium phosphate onto coir and jute fibers in a PLA matrix. They observed that the burning rate of biocomposite was decreased with increasing phosphate grafting rate [10].

In a previous work [4], we studied the fire behavior of polybutylene succinate (PBS) reinforced by various natural fibers. PBS was chosen as emerging biopolymer for which monomers from renewable resources are now available [12]. Moreover PBS exhibits interesting mechanical properties close to those of polyolefins and can be processed at low temperature $\left(120^{\circ} \mathrm{C}\right)$ [13], avoiding fiber thermal degradation $[14,15]$. In this paper, it was highlighted that, during combustion and above a certain amount of lignocellulosic fibers, a residue constituted by the skeleton of fibers is formed. This residue induces a controlled release of decomposition products and thus a relatively low heat release rate. Furthermore, it was evidenced that the barrier action of this residue could be greatly enhanced by addition of APP in the PBS matrix. The presence of APP leads to the formation of a strong char resulting from the dehydration of the natural fibers under the action of phosphoric acid. However, APP induces also a hot hydrolysis of PBS. Based on these observations, it was decided to investigate fiber surface modification as an alternative to the incorporation of FR in the matrix.

The present study focuses on the fire behavior of flame retarded PBS/flax fibers biocomposites. The objective of the paper is to investigate the flame retardant action of three phosphorous compounds that have been commonly used for cellulose fibers or textiles [16,17]: ammonium polyphosphate (APP), dihydrogen ammonium phosphate (DAP), and phosphoric acid (PA). A comparison between the additive route (incorporation of FR in the matrix) and the reactive route (grafting onto fiber surface) was attempted. Thermal and fire properties have been characterized by TGA, PCFC and cone calorimeter.

\section{Experimental}

\subsection{Materials}

Flax fibers (Fibras-S6D) were purchased from Fibres Recherche et Développement $\left(\right.$ FRD $\left.^{\circledR}\right)$. Dihydrogen ammonium phosphate (DAP-Prolabo), phosphoric acid (PA-Panreac) and ammonium polyphosphate (APP-Exolit AP 423-Clariant) were used as flame retardant agents. DAP and PA were also used as fiber surface treatment agents. The poly(1,4-butanediol succinate) (PBS film grade 1903F-Xinfu Pharm) was used as matrix.

\subsection{Fibers treatments}

\subsubsection{Pretreatment of the flax fibers}

Before chemical modification with the phosphorous compound, the flax fibers (Tfl) were pretreated with ethanol to remove waxes and pectin which ensure the cohesion of the flax beam [18].

In a reactor equipped with a condenser, $50 \mathrm{~g}$ of flax fibers and $1 \mathrm{~L}$ of ethanol were introduced. The mixture was heated under reflux
Table 1

Designation of the biocomposites.

\begin{tabular}{|c|c|c|c|c|c|c|}
\hline Designation & Sample & $\begin{array}{l}\text { PBS } \\
(w t \%)\end{array}$ & $\begin{array}{l}\text { APP } \\
(w t \%)\end{array}$ & $\begin{array}{l}\text { DAP } \\
(w t \%)\end{array}$ & $\begin{array}{l}\text { PA } \\
(\mathrm{wt} \%)\end{array}$ & $\begin{array}{l}\text { Tfl }{ }^{a} \\
(w t \%)\end{array}$ \\
\hline \multirow[t]{2}{*}{ FTfl } & Tfl-xDAP ${ }^{a}$ & & & $x$ & & $100-x$ \\
\hline & Tfl-yPA ${ }^{a}$ & & & & $y$ & $100-y$ \\
\hline PBS-Tfl & $\mathrm{PBS}+\mathrm{Tfl}$ & 70 & & & & 30 \\
\hline \multirow{2}{*}{$\begin{array}{l}\text { PBS-FTfl } \\
\quad \text { (reactive) }\end{array}$} & $\mathrm{PBS}+\mathrm{Tfl}-\mathrm{xDAP}{ }^{\mathrm{a}}$ & 70 & & $30 x$ & & $30(1-x)$ \\
\hline & $\mathrm{PBS}+$ Tfl-yPA ${ }^{\mathrm{a}}$ & 70 & & & $30 y$ & $30(1-y)$ \\
\hline \multirow{6}{*}{$\begin{array}{l}\text { FPBS-Tfl } \\
\quad \text { (additive) }\end{array}$} & $\mathrm{PBS}+\mathrm{Tfl}+3 \mathrm{DAP}$ & 68.5 & 3 & & & 28.5 \\
\hline & $\mathrm{PBS}+\mathrm{Tfl}+3 \mathrm{PA}$ & 68.5 & 3 & & & 28.5 \\
\hline & $\mathrm{PBS}+\mathrm{Tfl}+3 \mathrm{APP}$ & 68.5 & 3 & & & 28.5 \\
\hline & $\mathrm{PBS}+\mathrm{Tfl}+5 \mathrm{APP}$ & 65 & 5 & & & 30 \\
\hline & $\mathrm{PBS}+\mathrm{Tfl}+10 \mathrm{APP}$ & 60 & 10 & & & 30 \\
\hline & $\mathrm{PBS}+\mathrm{Tfl}+15 \mathrm{APP}$ & 55 & 15 & & & 30 \\
\hline
\end{tabular}

a $x$ and $y$ are $=2.5 ; 5 ; 7.5 ; 10 \mathrm{wt} \%$.

for $5 \mathrm{~h}$ with mechanical stirring. The liquid phase was eliminated and the flax fibers were dried at room temperature.

\subsubsection{Chemical modification of the flax fibers}

In a reactor equipped with a condenser, 45, 46.2, 47.5 and $48.7 \mathrm{~g}$ of pretreated flax fibers with 5.0, 3.8, 2.5 and $1.3 \mathrm{~g}$ of the treatment agent (for treatment at $10 \%, 7.5 \%, 5 \%$ and $2.5 \%$ ) were introduced, respectively. $1 \mathrm{~L}$ of ethanol was added. The mixture was heated under reflux for $5 \mathrm{~h}$ with mechanical stirring. The liquid phase was eliminated and the flax fibers were washed three times with ethanol and dried at room temperature. The natural fibers without fire retardant treatment were designated as Tfl and those functionalized with DAP or PA were designated as FTfl.

\subsection{Composite preparation}

\subsubsection{Processing of the flame retardant biocomposites}

The biocomposites were obtained by mixing PBS pellets and (functionalized or unfunctionalized) natural fibers in a Haake Rheomix internal mixer (100 rpm at $\left.110{ }^{\circ} \mathrm{C}\right)$. PBS was firstly introduced in the chamber of an internal mixer and mixed for 2.5 min until a constant torque was obtained. For the FPBS-Tfl systems (biocomposites fire retarded by additive route), the flame retardant agent was firstly added and mixed with the matrix for $2 \mathrm{~min}$. Then for all formulations, the fibers (Tfl or FTfl) were added progressively during $9 \mathrm{~min}$. After the final fiber addition, the mixing was extended for $2 \mathrm{~min}$. The total time of blending was around $15 \mathrm{~min}$. Biocomposites compositions and designations are given Table 1.

All materials were compression molded at 110 bars into $100 \times 100 \times 4 \mathrm{~mm}^{3}$ square sheets weighing around $50 \mathrm{~g}$.

The process retained to prepare biocomposites comprising PBS and flax fibers brings out two different routes; an additive route for which the flame retardant agent (DAP, PA or APP) is added in the melted PBS and flax fibers (Tfl) are further added. The biocomposite

Table 2

TGA values of PBS + Tfl and FPBS-Tfl.

\begin{tabular}{lllcc}
\hline Samples & $\begin{array}{l}T_{\text {deg }}(1 \mathrm{st}) \\
\left({ }^{\circ} \mathrm{C}\right)\end{array}$ & $\begin{array}{l}T_{\text {deg }}(2 \mathrm{nd}) \\
\left({ }^{\circ} \mathrm{C}\right)\end{array}$ & $\begin{array}{l}\operatorname{Res}_{600} \\
(\%)\end{array}$ & $\begin{array}{l}\text { Phosphorus } \\
\text { content }(\%)^{\mathrm{a}}\end{array}$ \\
\hline PBS + Tfl & 376.4 & 401.2 & 7.0 & 0 \\
PBS + Tfl + 3DAP & 309.5 & 393.7 & 8.7 & 2.7 \\
PBS + Tfl + 3PA & 259.1 & 376.3 & 11.7 & 3.2 \\
PBS + Tfl + 3APP & 276.8 & 379.3 & 11.7 & 3.2 \\
PBS + Tfl + 5APP & 288.6 & 378.9 & 15.5 & 5.3 \\
PBS + Tfl + 10APP & 288.6 & 357.6 & 20.0 & 10.6 \\
PBS + Tfl + 15APP & 276.4 & 333.1 & 13.3 & 16.0 \\
\hline
\end{tabular}

a The phosphorus content was calculated from the content of phosphorus on the treatment agents. This is the theoretical value. This value is relative to the fiber content. 
is designated by FPBS-Tfl. And a reactive route for which the flax fibers are first functionalized (and designated by FTfl) and further added to melted PBS. The biocomposite is designated by PBS-FTfl.

\subsection{Characterization}

\subsubsection{Thermogravimetric analysis (TGA)}

TGA was performed with a Perkin Elmer Pyris-1 Thermogravimetric analyzer instrument. Samples of weights around $10 \mathrm{mg}$ were heated from 50 to $900{ }^{\circ} \mathrm{C}$ at a heating rate of $10^{\circ} \mathrm{C} / \mathrm{min}$ under nitrogen atmosphere. Residual weight at $600{ }^{\circ} \mathrm{C}\left(\operatorname{Res}_{600}\right)$ and the temperature of the maximum of degradation $\left(T_{\mathrm{deg}}\right)$ were determined.

\subsubsection{Pyrolysis combustion flow calorimeter (PCFC)}

PCFC is a technique developed by Lyon and Walters [19] to investigate fire behavior of sample at microscopic scale. Sample weights of around $2 \mathrm{mg}$ are pyrolyzed at $1{ }^{\circ} \mathrm{C} / \mathrm{s}$ and the degradation products are transported by inert gas flux. Then, they are mixed with oxygen before entering in combustor at $900{ }^{\circ} \mathrm{C}$ where the products are completely oxidized. The heat release rate was measured as a function of temperature. The values of peak of heat release rate ( $\mathrm{pHRR})$, temperature of $\mathrm{pHRR}\left(T_{\mathrm{deg}}\right)$, total heat released (HR) which is the integral of the heat release rate over the duration of the experiment, and effective heat combustion (EHC), which corresponds to the heat released per gram of mass loss were determined.

\subsubsection{Cone calorimeter test}

A Fire Testing Technology (FTT) cone calorimeter was used to evaluate fire reaction properties. The $100 \times 100 \times 4 \mathrm{~mm}^{3}$ samples were exposed to a radiant heat flux of $35 \mathrm{~kW} / \mathrm{m}^{2}$. This flux corresponds to a common heat flux in a mild scenario. Heat release rate (HRR) was measured as a function of time and time to ignition (TTI), total heat release (THR), peak of heat release rate (pHRR), effective heat combustion (EHC), the quantity of char residue ( $\left.X_{\text {char }}\right)$ and the maximum average of heat emission (MARHE) were determined. The ARHE (average of heat emission) was calculated according to Eq (1) [20].

$\operatorname{ARHE}\left(t_{n}\right)=\frac{\sum_{2}^{n}\left(\left(t_{n}-t_{n-1}\right) \times \frac{q_{n}+q_{n-1}}{2}\right)}{t_{n}-t_{0}}$

\subsubsection{Elemental analyses}

For phosphorus elemental analysis, the samples were dissolved in an acid solution and analyzed by inductively coupled plasma atoms emission spectroscopy (ICP AES). Elemental analysis permits to measure the initial phosphorus content on treated flax fibers.

\subsubsection{EDX analyses}

Analysis of the phosphorus percentage in char residue was performed by Energy Dispersive X-ray spectroscopy (EDX) analysis using Oxford INCA Energy 300 system and a detector of $133 \mathrm{eV}$ resolution. EDX analysis permits to measure the phosphorus content in biocomposites residues after cone calorimeter test $\left(X_{\text {Pcond }}\right)$.

\subsubsection{Scanning electron microscopy (SEM)}

The micrographs of the char after cone calorimeter test were obtained using an environmental scanning electron microscope (FEI Quanta SEM) equipped with a scanning transmission electron microscopy detector (STEM). Micrographs were obtained under high vacuum at a voltage of $15 \mathrm{kV}$, with a spot size of $4.0 \mathrm{~nm}$ and a working distance of $10.1 \mathrm{~mm}$.
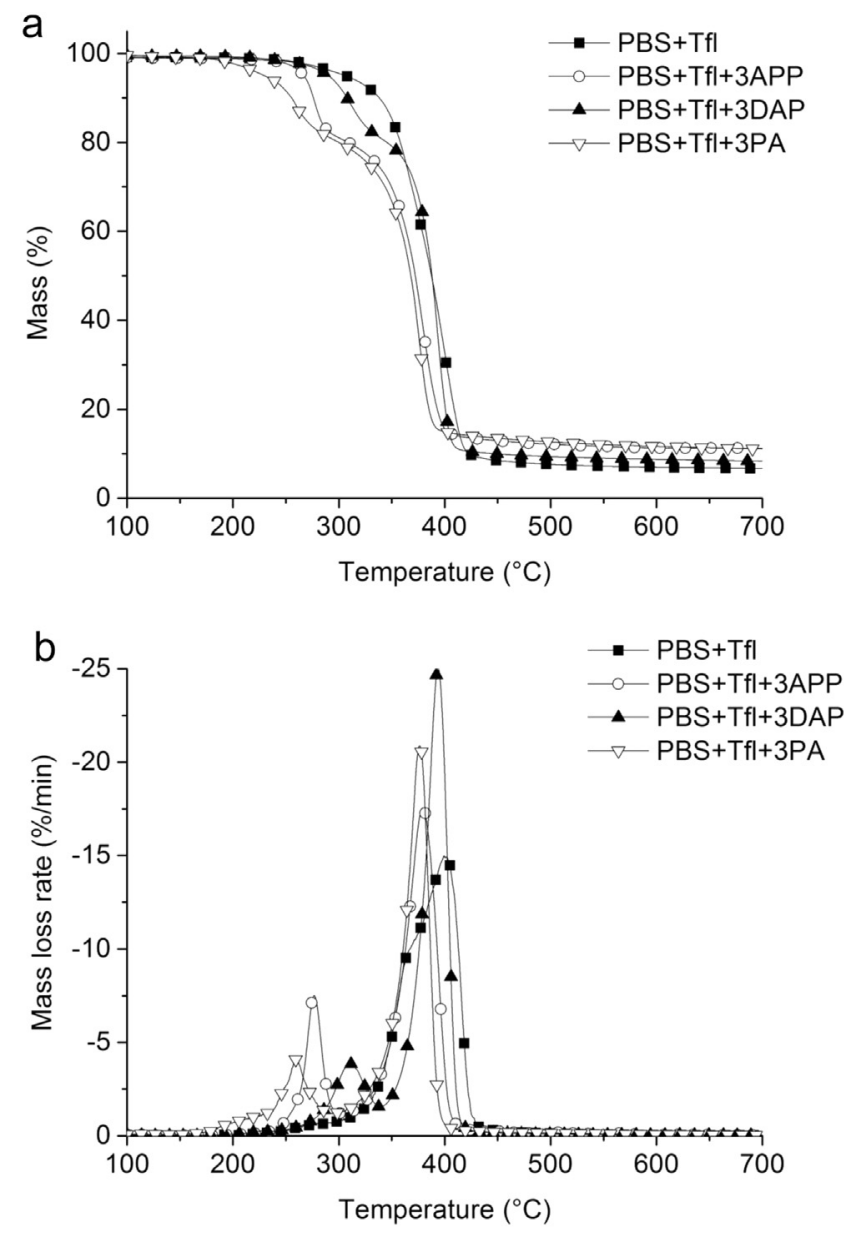

Fig. 1. TGA (a) and DTG (b) curves of PBS + Tfl and FPBS-Tfl.

\section{Results}

\subsection{Additive route}

The thermal degradation of biocomposites shown in Fig.1 occurs in two steps. For PBS $+\mathrm{Tfl}$, a shoulder is observed around $370{ }^{\circ} \mathrm{C}$ corresponding to the degradation of the flax fibers [4,14], while the main peak of degradation attributed the decomposition of PBS

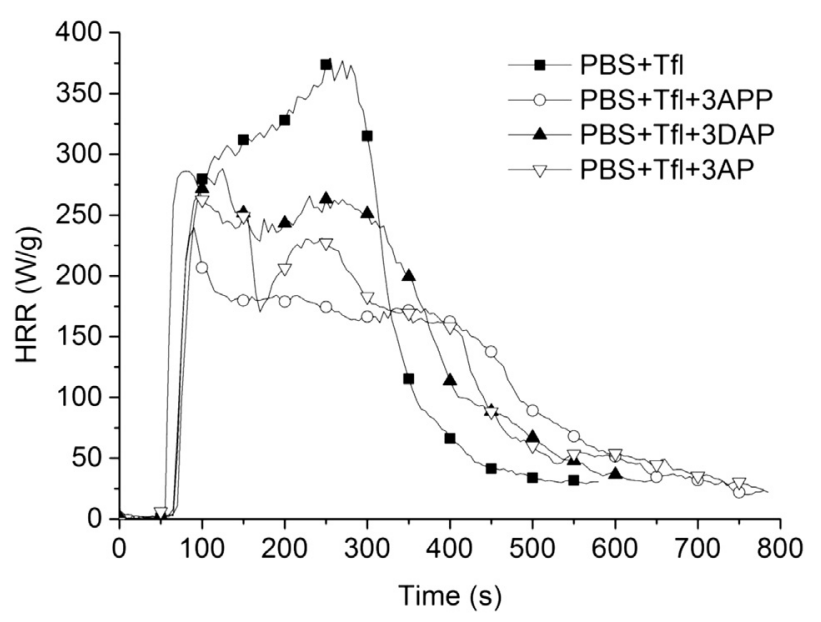

Fig. 2. Cone calorimeter curves of PBS + Tfl and FPBS-Tfl. 
Table 3

Cone calorimeter parameters of PBS + Tfl and FPBS-NF.

\begin{tabular}{lllllrl}
\hline Samples & $\begin{array}{l}\text { TTI } \\
(\mathrm{s})\end{array}$ & $\begin{array}{l}\text { pHRR } \\
\left(\mathrm{kW} / \mathrm{m}^{2}\right)\end{array}$ & $\begin{array}{l}\text { THR } \\
(\mathrm{kJ} / \mathrm{g})\end{array}$ & $\begin{array}{l}\text { EHC } \\
(\mathrm{kJ} / \mathrm{g})\end{array}$ & $\begin{array}{l}X_{\text {char }} \\
(\%)\end{array}$ & $\begin{array}{l}\text { MARHE } \\
\left(\mathrm{kW} / \mathrm{Xm}^{2}\right)\end{array}$ \\
\hline PBS + Tfl & 68 & 379.5 & 17.7 & 18.4 & 4.2 & 241.7 \\
PBS + Tfl + 3DAP & 64 & 288.2 & 16.4 & 17.8 & 7.8 & 197.6 \\
PBS + Tfl + 3PA & 51 & 286.2 & 17.1 & 17.8 & 3.8 & 184.3 \\
PBS + Tfl + 3APP & 64 & 239.7 & 15.5 & 17.3 & 10.7 & 147.5 \\
PBS + Tfl + 5APP & 55 & 207.6 & 14.0 & 16.8 & 16.8 & 127.4 \\
PBS + Tfl + 10APP & 62 & 192.8 & 11.6 & 15.1 & 23.2 & 109.5 \\
PBS + Tfl + 15APP & 72 & 150.0 & 8.8 & 12.6 & 30.2 & 103.9 \\
\hline
\end{tabular}

arises at $400{ }^{\circ} \mathrm{C}[4,13,21]$. The addition of APP, DAP and PA (3\%wt) in the biocomposite leads to two significant changes. Firstly the biocomposite starts to decompose earlier. The DTG curves show a first peak of degradation at $277^{\circ} \mathrm{C}, 309^{\circ} \mathrm{C}$ and $259^{\circ} \mathrm{C}$ for APP, DAP and PA containing PBS/flax composites, respectively. These peaks correspond to the premature degradation of flax. This decrease of the thermal stability of fibers could be assigned to the phosphorylation of cellulose by phosphorus acids which come from the decomposition of the FR. This reaction changes the degradation pathway of cellulose favoring dehydration of flax and then the formation of a carbonaceous residue [22,23]. Indeed, higher amounts of residues are obtained for APP and PA containing formulations (Res600 = 11.7\%wt) compared to PBS $+\mathrm{Tfl}$ (Res600 $=7.0 \% w t)$. Secondly, a shift of the main temperature of degradation, related to PBS decomposition, is observed (375$380{ }^{\circ} \mathrm{C}$ for FPBS-Tfl with $3 \%$ wt of additive against $400{ }^{\circ} \mathrm{C}$ for PBS + Tfl). The decrease of $T_{\text {deg }}$ is even more pronounced at high phosphorus as it is observed with PBS $+\mathrm{Tfl}+15 \mathrm{APP}$. This shift may be attributed to the hot hydrolysis of PBS also due to the degradation of the phosphorous compounds. It should be noted that the addition of phosphorous compounds in the pure PBS induces a similar effect without producing any char residue at high temperature (non-presented results).

This early degradation of the phosphonated biocomposite observed in TGA leads to a slight decrease of TTI in cone calorimeter tests (Fig. 2 and Table 3). According to the classification of Schartel and Hull [24], after ignition the shape of the HRR curve changes from an intermediate thick non-charring sample in the case of PBS + Tfl to a thick charring sample for the flame retarded biocomposites. This changing in behavior is confirmed by the observation of combustion residues (Fig. 3) which reveals the formation of a char layer, that limits heat and mass transfer. The barrier effect results in a strong decrease of the pHRR (decrease of $24 \%-37 \%$ ) as well as a significant reduction of MARHE (18\%-39\%) for all FPBS-Tfl formulations. It can be noticed that the char amount varies with the phosphorous compound, PA, DAP and APP giving 3.8\%, 7.8\% and 10\% of residue, respectively. From Table 4, it is noteworthy that initial phosphorus content is not the only parameter governing the residue amount since the presence of PA leads to a lower residue than
Table 4

Fraction of phosphorus content in the vapor and condensed phase ( $f_{\text {Pcond }}$ et $f_{\text {Pgas }}$ ).

\begin{tabular}{llcccc}
\hline Sample & $X_{\text {Pini }}(\%)$ & $X_{\text {Pcond }}(\%)$ & $X_{\text {char }}(\%)$ & $f_{\text {Pcond }}$ & $f_{\text {Pvap }}$ \\
\hline PBS + Tfl + 3APP & 0.96 & 8.58 & 10.7 & 0.95 & 0.05 \\
PBS + Tfl + 3DAP & 0.81 & 9.48 & 7.8 & 0.91 & 0.09 \\
PBS + Tfl + 3PA & 0.95 & 13.88 & 3.8 & 0.55 & 0.45 \\
\hline
\end{tabular}

APP. The partition of phosphorus between condensed and vapor phase has been estimated using the method proposed by Vahabi et al. [25]. The fractions of phosphorus in condensed and gaseous phase ( $f_{\text {Pcond }}$ and $f_{\text {Pgas }}$, respectively) were calculated from the initial phosphorus content $\left(X_{\text {Pini }}\right)$, the char residue $\left(X_{\text {char }}\right)$ and the phosphorus content in residue determined by EDX ( $\left.X_{\text {Pcond }}\right)$ according to Eq. (1) and Eq. (2). All contents are expressed in weight fractions.

$f_{\text {Pcond }}=\frac{X_{\text {char }} \times X_{\text {Pcond }}}{X_{\text {Pini }}}$

$f_{\text {Pvap }}=1-f_{\text {Pcond }}$

From Table 4, it can be seen that phosphorus from APP and DAP contributes almost exclusively to the char formation $\left(f_{\text {Pcond }}\right.$ are close to 1) whereas with PA almost half of the phosphorus content $(45 \%)$ is evolved in the gaseous phase. Indeed, the low ebullition point of PA $\left(158{ }^{\circ} \mathrm{C}\right)$ decreases the degradation temperature of PBS + Tfl +3 PA (as shown in Fig. 1) and increases the part of the phosphorus release in the gaseous phase. However, no particular action of this phosphorous compound in the vapor phase is observed since the effective heat of combustion (EHC) of biocomposites remains unchanged around $18 \mathrm{~kJ} / \mathrm{g}$ (Table 3 ).

From this first part, it can be concluded that the presence of phosphorous compound in the matrix is likely to induce the charring of lignocellulosic fibers and thus to produce a significant flame retardant effect in the biocomposite. The magnitude of this effect depends on the phosphorus content and on the volatility of the product. Besides, the presence of the phosphorous compound tends to decrease the thermal stability of the PBS matrix.

\subsection{Reactive route}

Among the three previous phosphorous molecules, two of them (DAP and PA) can be easily solubilized in ethanol. Therefore they have been selected to be used as grafting agents for flax fibers. Grafted fibers have been prepared using the protocol described in the experimental section. The incorporation rate was varied between 2.5 and $10 \%$ of the flax mass. However, the experimental grafting yield (measured by elemental analyses) was lower than expected ( $<40 \%$ of the theoretical grafting). Hence, the phosphorus quantity grafted onto flax varied only up to $1.13 \%$ wt for DAP and up
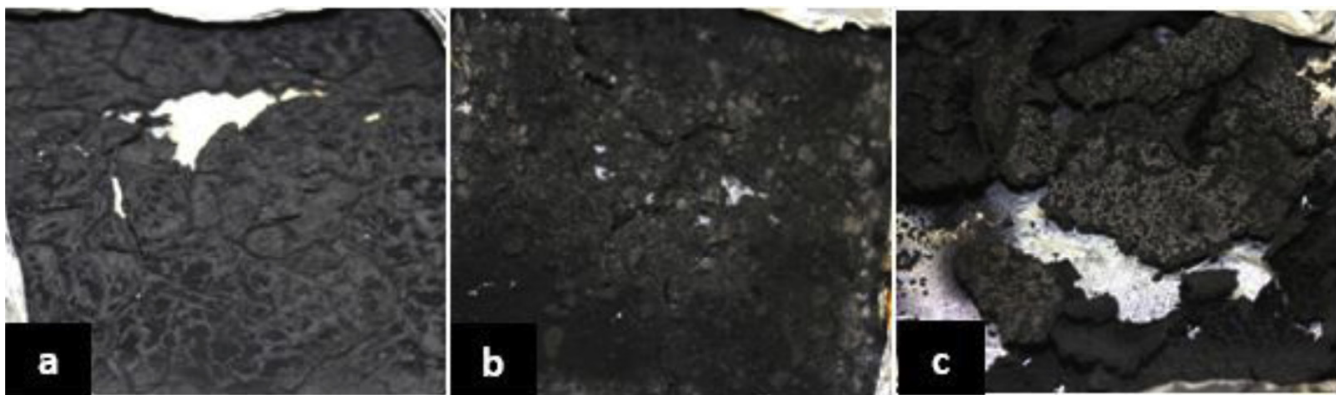

Fig. 3. Residues of FPBS + Tfl after cone calorimeter tests: (a) PBS $+\mathrm{Tfl}+\mathrm{APP}$, (b) PBS $+\mathrm{Tfl}+\mathrm{DAP}$, (c) PBS $+\mathrm{Tfl}+\mathrm{PA}$ 


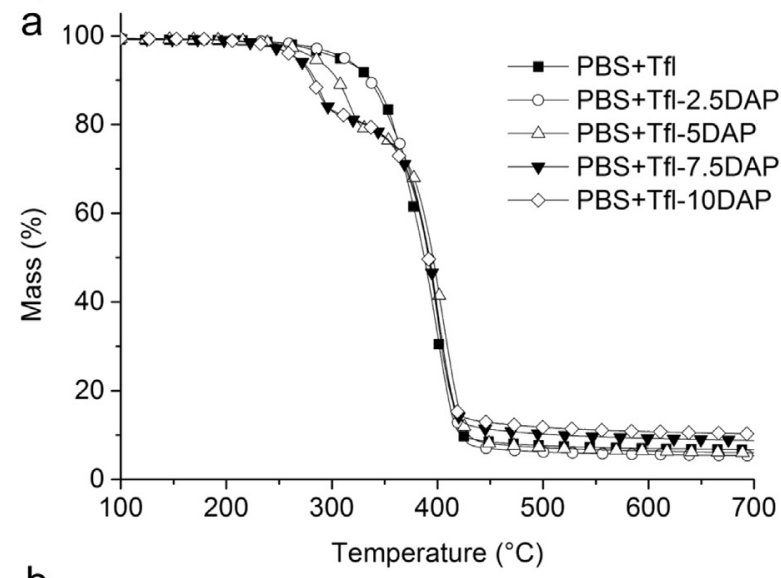

b

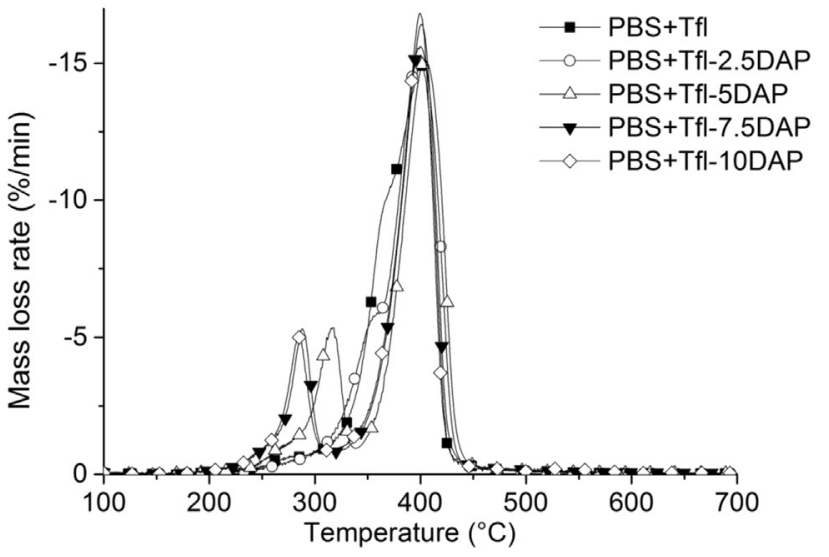

Fig. 4. TGA (a) and DTG (b) curves of PBS + Tfl and PBS + Tfl-xDAP $(x=2.5 ; 5 ; 7.5$ and 10).

to $0.52 \%$ wt for PA and the final phosphorus content in the biocomposites was at most $0.34 \%$ wt for DAP and $0.16 \%$ wt for PA.

Thermal analysis reveals that when DAP or PA is grafted onto flax, biocomposites still degrade in two steps (Fig. 4 and Table 5). The high temperature peak, assigned to the PBS decomposition, remains constant around $400{ }^{\circ} \mathrm{C}$. Thus it can be concluded that grafting of phosphorus onto flax prevents from PBS hot hydrolysis and makes the biocomposite more stable at high temperature. It can be also observed that the first peak of degradation, corresponding to fiber decomposition, is progressively shifted to lower temperature with increasing grafting rate. The early decomposition of grafted flax is also confirmed by PCFC measurements (Table 6). At the same time, the high temperature residue increases with increasing phosphorus grafting rate, up to $10.8 \%$ in the case of DAP.

Table 5

TGA parameters of PBS + Tfl and PBS-FTfl.

\begin{tabular}{llllrl}
\hline Samples & $\begin{array}{l}T_{\text {deg }} \\
(1 \mathrm{st}){ }^{\circ} \mathrm{C}\end{array}$ & $\begin{array}{l}T_{\text {deg }} \\
(2 \mathrm{nd})\left({ }^{\circ} \mathrm{C}\right)\end{array}$ & $\begin{array}{l}\operatorname{Res}_{600} \\
(\%)\end{array}$ & $\begin{array}{l}\text { Phosphorus } \\
\text { content }(\%)\end{array}$ \\
\hline \multirow{5}{*}{ PBS + FTfl }
\end{tabular}

\footnotetext{
a Calculated by elemental analysis. Values are relative to the fiber content.
}

Table 6

PCFC values of PBS + Tfl and PBS + FTfl.

\begin{tabular}{llllll}
\hline Samples & $\begin{array}{l}T_{\text {deg }}(1 \mathrm{st}) \\
\left({ }^{\circ} \mathrm{C}\right)\end{array}$ & $\begin{array}{l}T_{\text {deg }}(2 \mathrm{nd}) \\
\left({ }^{\circ} \mathrm{C}\right)\end{array}$ & $\begin{array}{l}\mathrm{HR} \\
(\mathrm{kJ} / \mathrm{g})\end{array}$ & $\begin{array}{l}\mathrm{pHRR} \\
(\mathrm{W} / \mathrm{g})\end{array}$ & $\begin{array}{l}\mathrm{EHC} \\
(\mathrm{kJ} / \mathrm{g})\end{array}$ \\
\hline PBS + Tfl & 393.3 & 421.8 & 16.3 & 264.7 & 17.5 \\
PBS + Tfl-2.5DAP & 355.2 & 419.0 & 17.2 & $56.6 / 296.8$ & 18.2 \\
PBS + Tfl-5DAP & 314.2 & 422.0 & 16.4 & $59.1 / 280.9$ & 17.5 \\
PBS + Tfl-7.5DAP & 294.1 & 418.8 & 14.3 & $47.0 / 271.0$ & 15.8 \\
PBS + Tfl-10DAP & 286.8 & 413.4 & 15.1 & $49.5 / 300.3$ & 16.9 \\
PBS + Tfl-2.5PA & 382.2 & 417.5 & 16.1 & $83.7 / 279.6$ & 17.2 \\
PBS + Tfl-5PA & 371.1 & 417.5 & 15.8 & $58.6 / 272.2$ & 16.9 \\
PBS + Tfl-7.5PA & 349.9 & 419.1 & 15.7 & $49.8 / 280.3$ & 16.8 \\
PBS + Tfl-10PA & 351.3 & 422.4 & 16.4 & $46.6 / 319.6$ & 17.7 \\
\hline
\end{tabular}

In the case of PA, the phosphorus grafting is quasi equal for all treated fibers, which induced no variation of the amount of residue.

As soon as phosphorus is added, the degradation mechanism of flax starts to change from depolymerization to dehydration leading to a decrease of the thermal stability $[22,23]$. However, at low phosphorus content (Tfl-2.5DAP), it can be noticed that the impact of dehydration on char formation is not efficient. Indeed, it may be assumed that if dehydration remains limited, the number of created unsaturations is not sufficient to induce an enhanced charring.

Fig. 5 shows the results from cone calorimeter experiments for the PBS $+\mathrm{Tfl} / \mathrm{xDAP}$ ( $x$ varying between 2.5 and 10\%). It can be observed that, as DAP grafting rate increases, pHRR and MAHRE decrease whereas the char residue increases (Table 7). It should be remarked that the char residue from cone calorimeter is consistent with high temperature residue obtained by TGA measurements. Furthermore, the HRR curve shape progressively changes from a non-charring behavior to a thick charring behavior. Thus, it can be concluded that phosphorus grafting with DAP favors the formation of a protective char layer acting as barrier for mass and heat transfer. However, it should be underlined that at low phosphorus content an adverse effect is observed since the behavior is close to that of the ungrafted flax composite and the pHRR is even higher. This result is in agreement with TGA measurements for which a decrease of thermal stability was evidenced without any increase of the char yield. The same effect is noted for PA grafted biocomposites.

The observation of the combustion residues highlights the formation of a charred layer which is all the more important and cohesive that the amount of phosphorus increases (Fig. 6). These pictures confirm that a minimal quantity of phosphorus is required

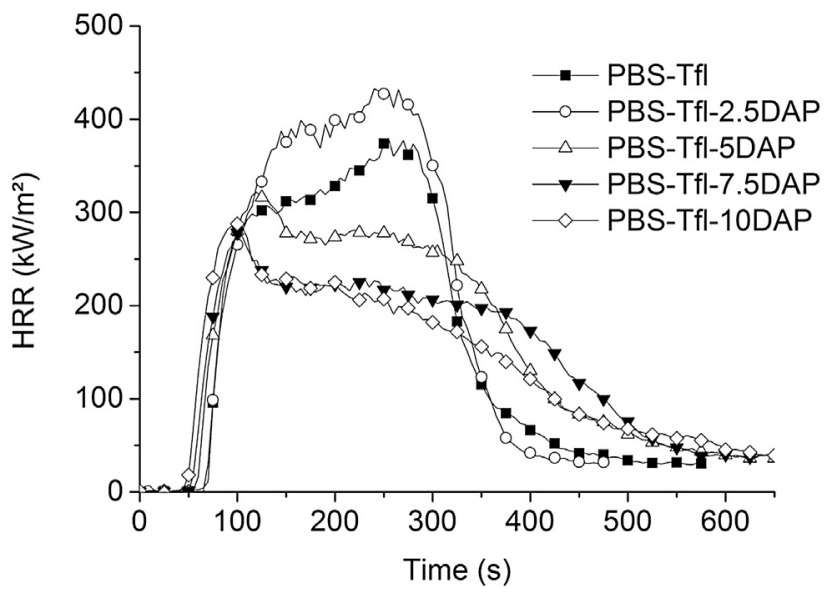

Fig. 5. Cone calorimeter curves of PBS + Tfl-xDAP (with $x=2.5 ; 5 ; 7.5 ; 10$ ). 
Table 7

Cone calorimeter parameters of PBS + Tfl and PBS + FTfl.

\begin{tabular}{lllllll}
\hline Samples & $\begin{array}{l}\text { TTI } \\
(\mathrm{s})\end{array}$ & $\begin{array}{l}\text { pHRR } \\
\left(\mathrm{kW} / \mathrm{m}^{2}\right)\end{array}$ & $\begin{array}{l}\text { THR } \\
(\mathrm{kJ})\end{array}$ & $\begin{array}{l}\text { EHC } \\
(\mathrm{kJ} / \mathrm{g})\end{array}$ & $\begin{array}{l}X_{\text {char }} \\
(\%)\end{array}$ & $\begin{array}{l}\text { MARHE } \\
\left(\mathrm{kW} / \mathrm{m}^{2}\right)\end{array}$ \\
\hline PBS + Tfl & 68 & 379.5 & 17.7 & 18.4 & 3.1 & 241.7 \\
PBS + Tfl-2.5DAP & 63 & 433 & 18.0 & 18.9 & 4.5 & 277.5 \\
PBS + Tfl-5DAP & 56 & 321.8 & 17.3 & 18.4 & 6.1 & 216.1 \\
PBS + Tfl-7.5DAP & 50 & 278.2 & 16.1 & 17.5 & 8.2 & 181.8 \\
PBS + Tfl-10DAP & 64 & 314.5 & 16.1 & 17.7 & 9.2 & 178.6 \\
PBS + Tfl-2.5PA & 71 & 360 & 18.1 & 18.9 & 3.2 & 242.8 \\
PBS + Tfl-5PA & 66 & 379.3 & 18.2 & 18.9 & 3.5 & 244.9 \\
PBS + Tfl-7.5PA & 62 & 379.5 & 18.3 & 19.2 & 4.5 & 243.2 \\
PBS + Tfl-10PA & 60 & 365.5 & 18.1 & 18.9 & 4 & 243.6 \\
\hline
\end{tabular}

to obtain a layer covering and protecting the whole sample. EDX analysis performed on combustion residue evidences the presence of a significant amount of phosphorus. Using the same method as in the previous section, it is possible to claim that almost all of phosphorus stays in the condensed phase.

\subsection{Comparison between additive and reactive route}

In order to compare the additive and the reactive routes, the variation of the temperature of the first and second decomposition peaks as well as the amount of residue on cone calorimeter tests are plotted as a function of the phosphorus content, relative to the fiber content in Fig. 7. In the case of PA used as additive, the phosphorus content was supposed to be $55 \%$ of its initial value since an important part of PA was released in the vapor phase as shown in Section 3.1.

It is noted that the first decomposition temperature decreases down to $280{ }^{\circ} \mathrm{C}$ as phosphorus content increases. When phosphorus represents more than $1 \%$ of the flax weight, the degradation temperature seems to reach a constant value. As previously explained, the decrease of $T_{\mathrm{deg}}$ should correspond to the progressive change of degradation pathway of cellulose from depolymerization to dehydration. Above a certain amount of phosphorus (approximately 1\%), degradation has completely switched to
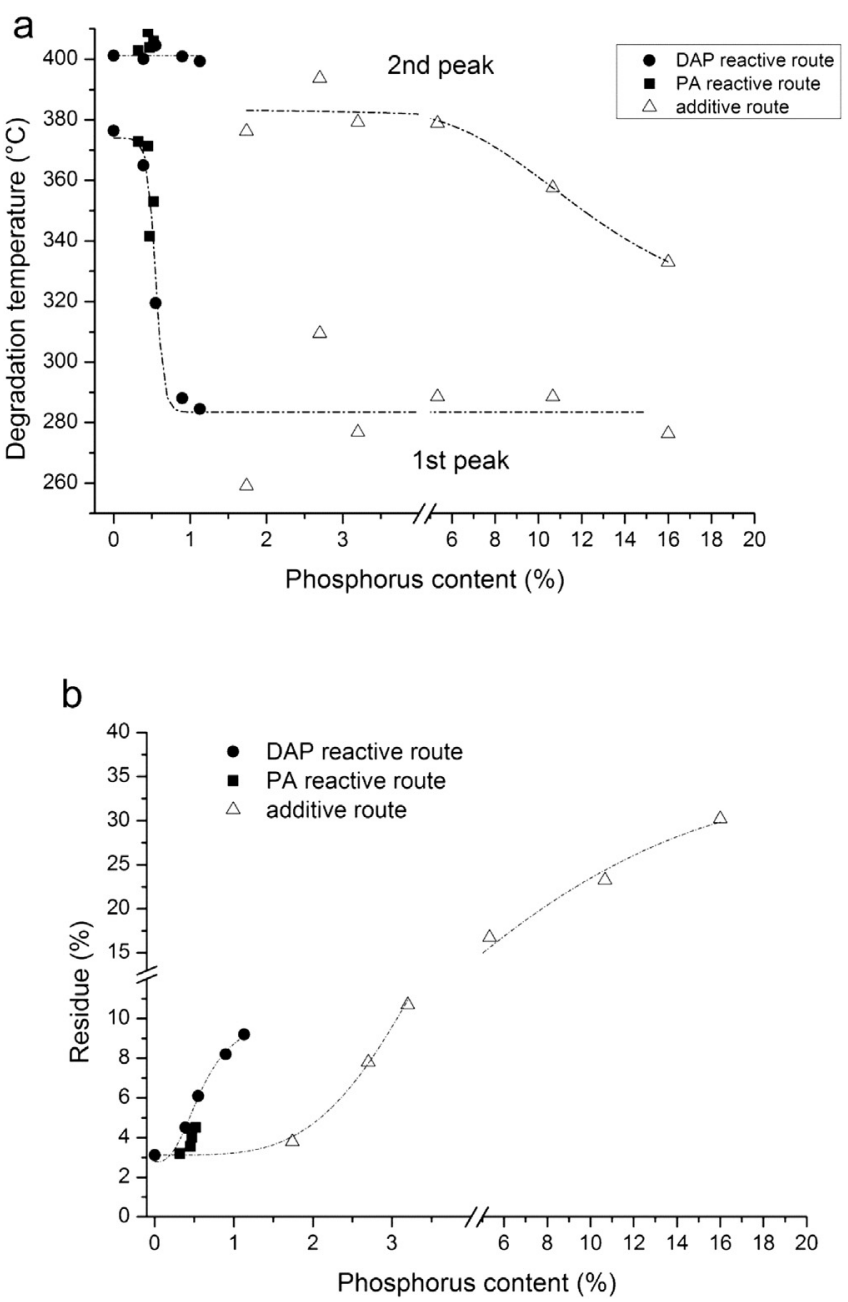

Fig. 7. (a) Temperature of the 1 st and 2 nd decomposition peaks and (b) amount of char residue of cone calorimeter test versus phosphorus content (relative to fibers content).

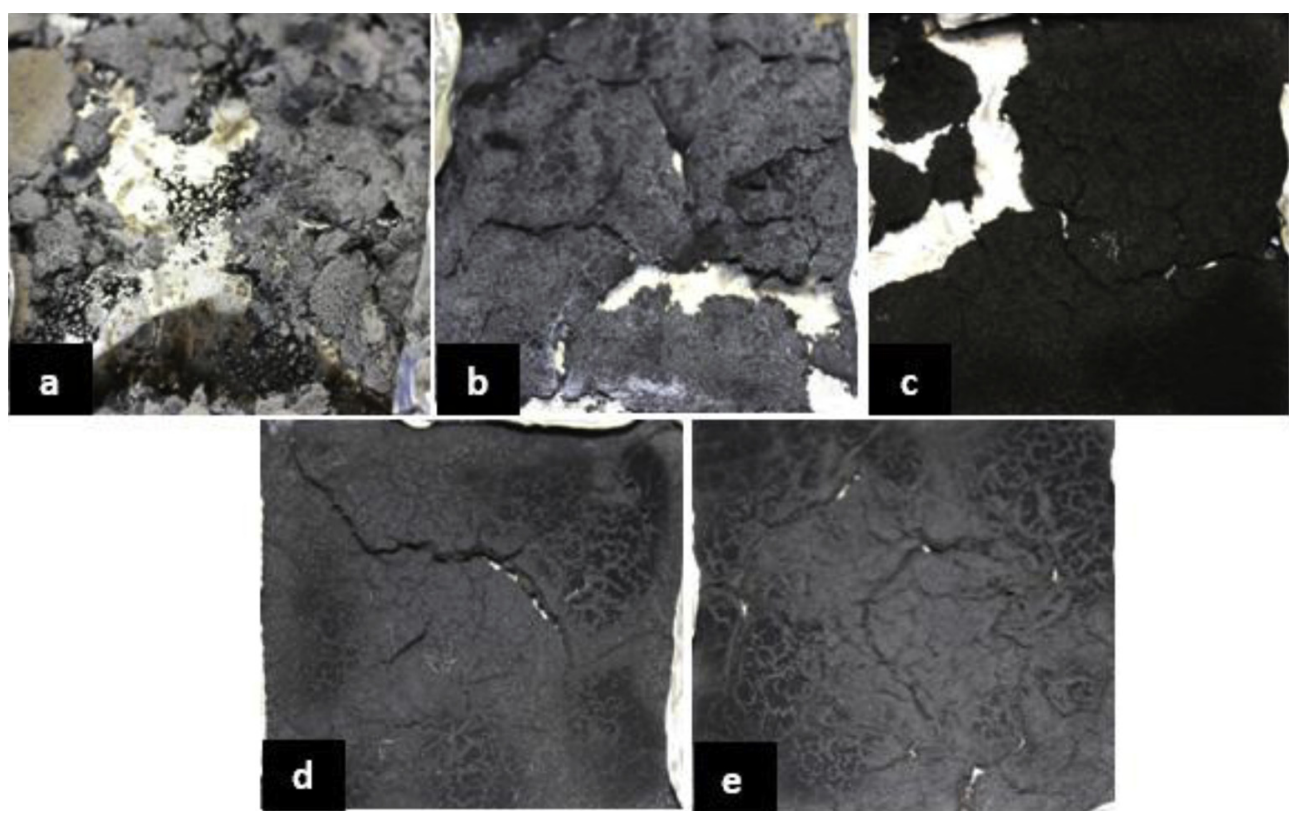

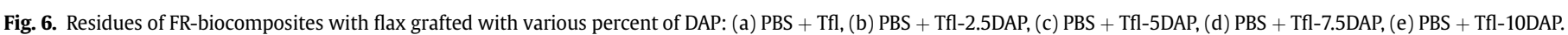



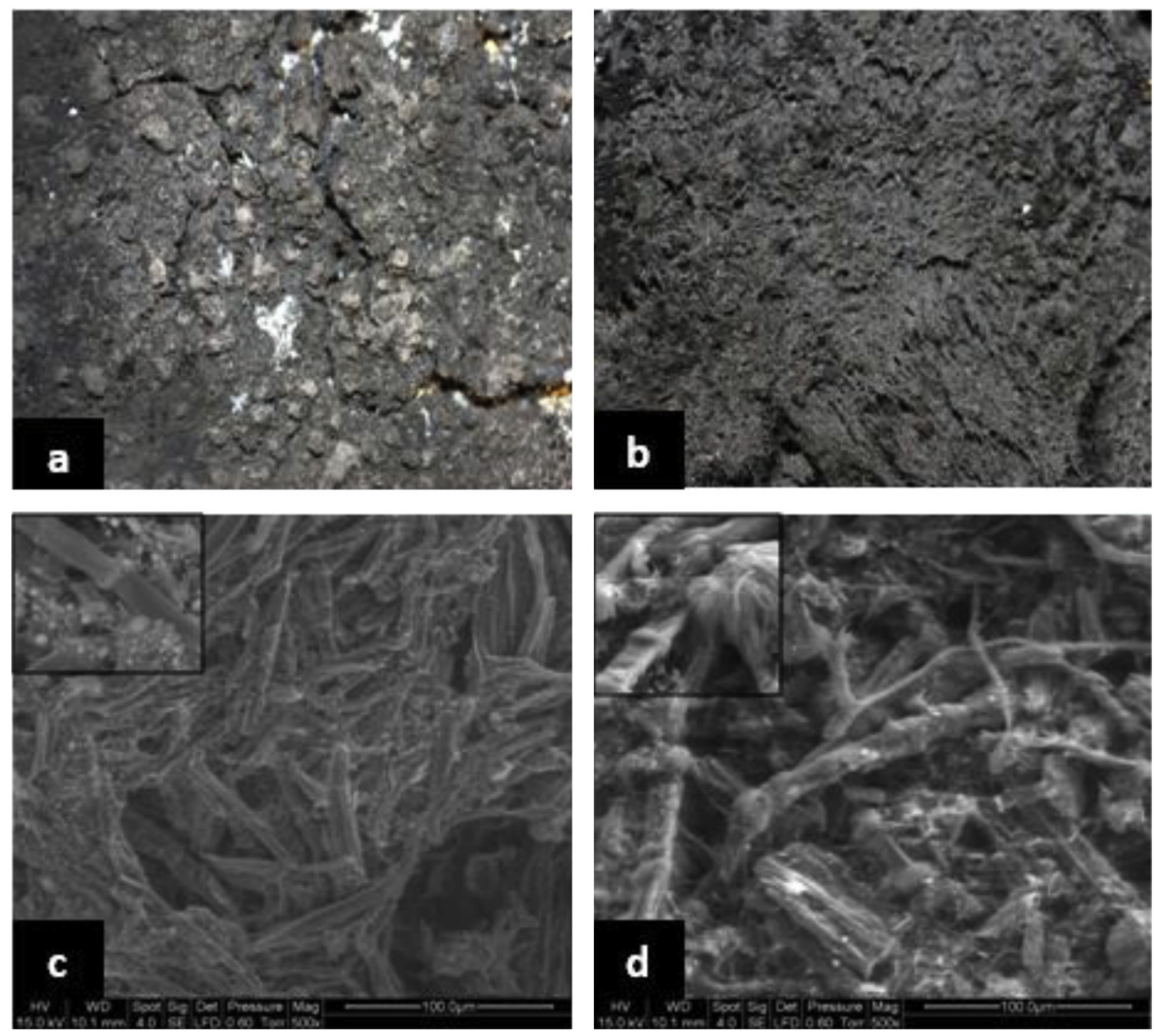

Fig. 8. Comparison of the morphology of the residue of DAP (a) and (c) incorporated in biocomposites or (b) and (d) grafted onto fibers.

dehydration. Thus, in the case of the additive route, the degradation of flax occurs at lower temperature because the phosphorus content is over this threshold.

It can be remarked that the temperature of the second degradation step is almost constant whatever the grafting rate. This result suggests that PBS decomposition is not affected by the presence of phosphorus when the flame retardant compound is located on the fiber surface. On the contrary, when the phosphorous compound is added in the matrix, it induces a significant decrease of PBS decomposition temperature due to hot hydrolysis (Table 2 ). At very high phosphorus content (16\%), the degradation temperature of PBS can be as low as $340{ }^{\circ} \mathrm{C}$.

Fig. $7 \mathrm{~b}$ shows that the combustion residue progressively increases from $3 \%$ wt to approximately $10 \% \mathrm{wt}$ for the reactive route and $30 \%$ for the additive route, when increasing the phosphorus content. However, it is noteworthy that the residue increase depends on whether phosphorus is incorporated by additive or reactive route. When the additive route is used, the residue enhancement occurs between 1.5 and 3\%wt of phosphorus, which is in agreement with Horrocks and Zhang [26]. On the opposite, using the reactive route enables to shift the residue increase to lower phosphorus content (between 0.5 and 1\%wt). From cone calorimeter data and residue observation (Fig. 8), it is obvious that the improvement of the fire behavior in terms of pHRR or MAHRE is closely related to the amount of phosphorus and to the cohesion of the char residue acting as a protective layer. Hence, it can be concluded that the reactive route enables a targeted action of phosphorus during flax decomposition leading to the promotion of efficient barrier layer at a lower amount of phosphorus compared to the additive route (Fig. 9 and Fig. 8). The main restriction of the reactive route lies in the limited amount of phosphorus that can be incorporated by grafting.

\section{Conclusion}

In this study, the effect of phosphorous flame retardants localization (grafted onto fibers or added in the matrix) on the flame retardancy of PBS/flax biocomposites was investigated. In the two cases, an earlier temperature of degradation of flax fibers was observed when phosphorus is added. This loss of thermal stability is linked to the phosphorylation of cellulose and the changing of degradation pathway from depolymerization to dehydration. The phosphorylation leads to the charring of flax fibers and the improvement of the fire behavior of PBS/flax biocomposites $\left(X_{\text {char }}=3.1 \mathrm{wt} \%\right.$ against $9.2 \mathrm{wt} \%, \mathrm{pHRR}=379.5 \mathrm{~kW} / \mathrm{m}^{2}$ against

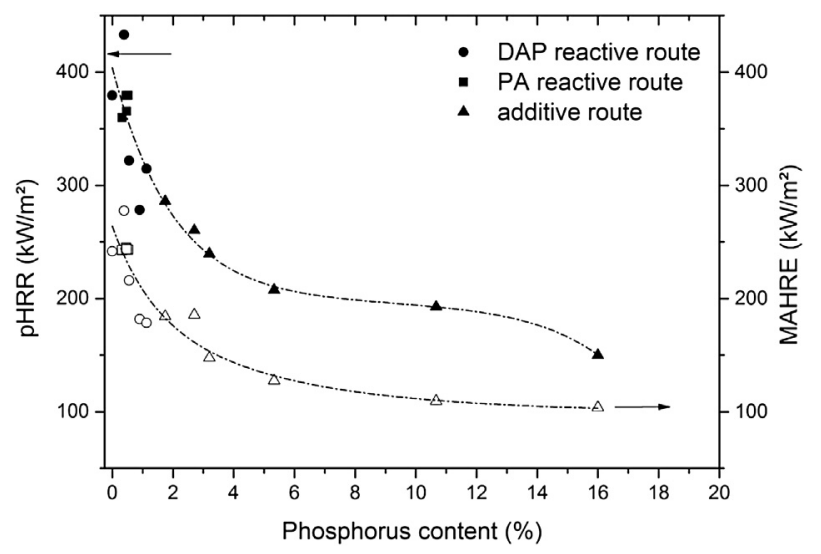

Fig. 9. pHRR and MARHE as a function of phosphorus content (relative to the fibers content). 
$314.5 \mathrm{~kW} / \mathrm{m}^{2}$ and MARHE $=241.7 \mathrm{~kW} / \mathrm{m}^{2}$ against $178.6 \mathrm{~kW} / \mathrm{m}^{2}$ for PBS + Tfl and PBS + Tfl-10DAP, respectively). The charring was highlighted to be effective at lower phosphorus content using the reactive route due to the proximity between flax and phosphorous compound. The reactive route was also proved to weakly impinge PBS decomposition while the polymer matrix starts to degrade earlier in the additive route. To go further on the understanding of interactions between phosphorus treatment agent, flax and PBS, it could be interesting to graft a phosphorous polymer onto natural fibers.

\section{References}

[1] Van de Velde K, Kiekens P. Biopolymers: overview of several properties and consequences on their applications. Polym Test 2002;21(4):433-42.

[2] Cantero G, Arbelaiz R, Llano-Ponte R, Mondragon I. Effects of fibre treatment on wettability and mechanical behaviour of flax/polypropylene composites Compos Sci Technol 2003;63(9):1247-54.

[3] Chapple S, Anandjiwala R. Flammability of natural fiber-reinforced composites and strategies for fire retardancy: a review. J Thermoplast Compos 2010; 23(6):871-93.

[4] Dorez G, Taguet A, Ferry L, Lopez-Cuesta JM. Thermal and fire behavior of natural fibers/PBS biocomposites. Polym Degrad Stab 2012;98(1):87-95.

[5] Kozłowski R, Władyka-Przybylak M. Flammability and fire resistance of composites reinforced by natural fibers. Polym Adv Technol 2008;19(6):446-53.

[6] Schartel B, Braun U, Schwarz U, Reinemann S. Fire retardancy of polypropylene/flax blends. Polymer 2003;44(20):6241-50.

[7] Hapuarachchi TD, Peijs T. Multiwalled carbon nanotubes and sepiolite nanoclays as flame retardants for polylactide and its natural fibre reinforced composites. Compos Appl Sci Manuf 2010;41(8):954-63.

[8] Shumao L, Jie R, Hua Y, Tao Y, Weizhong Y. Influence of ammonium polyphosphate on the flame retardancy and mechanical properties of ramie fiberreinforced poly(lactic acid) biocomposites. Polym Int 2009;59(2):242-8.

[9] Matkó S, Toldy A, Keszei S, Anna P, Bertalan G, Marosi G. Flame retardancy of biodegradable polymers and biocomposites. Polym Degrad Stabil 2005;88(1): $138-45$.

[10] Suardana NPG, Ku MS, Lim JK. Effects of diammonium phosphate on the flammability and mechanical properties of bio-composites. Mater Des 2011;32(4):1990-9.
[11] Chen D, Li J, Ren J. Combustion properties and transference behavior of ultrafine microencapsulated ammonium polyphosphate in ramie fabricreinforced poly(L-lactic acid) biocomposites. Polym Int 2011;60(4):599-606.

[12] Zeikus JG, Jain MK, Elankovan P. Biotechnology of succinic acid production and markets for derived industrial products. Appl Microbiol Biotechnol 1999;51(5):545-52.

[13] Chrissafis K, Paraskevopoulos KM, Bikiaris DN. Thermal degradation mechanism of poly(ethylene succinate) and poly(butylene succinate): comparative study. Thermochim Acta 2005:435(2):142-50.

[14] Manfredi LB, Rodríguez ES, Wladyka-Przybylak M, Vázquez A. Thermal degradation and fire resistance of unsaturated polyester, modified acrylic resins and their composites with natural fibres. Polym Degrad Stab 2006;91(2):255-61.

[15] Moriana R, Vilaplana F, Karlsson S, Ribes-Greus A. Improved thermomechanical properties by the addition of natural fibres in starch-based sustainable biocomposites. Compos Appl Sci Manuf 2011:41(1):30-40.

[16] Horrocks AR. Flame retardant challenges for textiles and fibres: new chemistry versus innovatory solutions. Polym Degrad Stab 2011;46(3):377-92.

[17] Gaan S, Sun G. Effect of phosphorus flame retardants on thermo-oxidative decomposition of cotton. Polym Degrad Stab 2007;92(6):969-74.

[18] Baley S, Busnet F, Grohens Y, Sire O. Influence of chemical treatments on surface properties and adhesion of flax fibre-polyester resin. Compos Appl Sci Manuf 2006:37(10):1626-37.

[19] Lyon R, Walters RN. Pyrolysis combustion flow calorimetry. J Anal Appl Pyrol 2004;71(1):27-46.

[20] Didane N, Giraud S, Devaux E. Fire performances comparison of back coating and melt spinning approaches for PET covering textiles. Polym Degrad Stab 2012;97(7):1083-9.

[21] Shih YF. Thermal degradation and kinetic analysis of biodegradable PBS/ multiwalled carbon nanotube nanocomposites. J Polym Sci Pol Phy 2009;47: 1231-9.

[22] Lewin M, Weil ED. Fire retardant materials. In: Horrocks AR, Price D, editors. Mechanisms and modes of actions in flame retardancy of polymers, 2 . Boca Raton: CRC Press LLC; 2001.

[23] Lecoeur E, Vroman I, Bourbigot S, Lam TM, Delobel R. Flame retardant formulations for cotton. Polym Degrad Stab 2001;47(3):487-92.

[24] Schartel B, Hull TR. Development of fire-retarded materials - interpretation of cone calorimeter data. Fire Mater 2007;31(5):327-54.

[25] Vahabi H, Fery L, Longuet C, Sonnier R, Negrell-Guirao C, David G, et al. Theoretical and empirical approaches to understanding the effect of phosphonate groups on the thermal degradation for two chemically modified PMMA. Eur Polym J 2012;48(3):604-6012.

[26] Horrocks AR, Zhang S. Enhancing polymer char formation by reaction with phosphorylated polyols. 1. Cellulose. Polymer 2001;42:8025-33. 